\title{
Analysis of the Decoupling Relationship between China's Economy and the Indicators of the Power Industry from National and Provincial Aspects
}

\author{
Yong Li ${ }^{1}$, Huisheng $\mathrm{Gao}^{2}$, Wei Sun ${ }^{2 *}$ \\ ${ }^{1}$ Shaoxing Power Supply Company of State Grid Zhejiang Electric Power Co., Yuecheng District, Shaoxing, China \\ ${ }^{2}$ School of Electrical and Electronic Engineering, North China Electric Power University, Baoding, China
}

Received: 17 December 2019

Accepted: 19 February 2020

\begin{abstract}
In China, the power industry is a major fossil-energy consumption sector and carbon dioxide emitter putting great pressure on the environment. To realize the sustainable development of the power industry and economy, it is necessary to investigate the decoupling relationship between the economic and the power industry-related indicators (i.e., the power generation of carbon dioxide emissions and electric carbon productivity). This study employs the Tapio decoupling technique to conduct the analysis at national and provincial levels, covering the period of 2000-2016. Empirical results show that:

1) In our work there are four decoupling statuses existing among the total eight decoupling statuses, showing alternating and periodic characteristics.

2) The decoupling status evolution between the economy and carbon dioxide emissions for 30 provinces shows regional features, with similarities and differences due to the local economic mode, natural resources and the echo to the central government policies.

3) The decoupling status can also reflect the impact of national and even international policies. The results could help the central and local governments formulate targeted measures to reduce carbon dioxide from the power industry and increase electric carbon productivity without compromising the economy to achieve the coordination of the economy and the environment.
\end{abstract}

Keywords: carbon dioxide emissions, power industry, electric carbon productivity, decoupling analysis, provincial level

\section{Introduction}

Carbon dioxide $\left(\mathrm{CO}_{2}\right)$, which is responsible for $58.8 \%$ of all greenhouse gases (GHG) [1], is the main cause

*e-mail: hdprettyweiwei@126.com of climate change and many environmental problems - especially coal-related $\mathrm{CO}_{2}$ emissions coming from the burning of fossil fuels in coal-based power plants, which contribute to the bulk of total emissions [2].

In China, the situation is even more challenging. The reasons involve the resources endowment and high electricity demand [2]. First, due to the natural resources and energy policy, coal and its products become the 
main fuel for thermal power plants generating more than $70 \%$ of national electricity [4], which makes the power industry the major source of $\mathrm{CO}_{2}$ emissions in China, with the proportion of about $40 \%$ to the national total emissions. Second, electricity is the pillar of the national continuous and robust economic development, as well as social development, industrialization and urbanization. Since the implementation of economic reform and open policy in 1978, China has experienced magically rapid economic development with an average annual growth rate of about $8 \%$ [5]. To satisfy the booming economic growth, the installed capacity and electricity generation has increased from 65.9 million kilowatts $(\mathrm{kW})$ and 285.5 billion kilowatt hours (kWh) in 1980 to 1777.08 million $\mathrm{kW}$ and 6417.1 billion $\mathrm{kWh}$ in 2017, respectively [4]. Correspondingly, national electricity consumption increased from 1347.2 billion $\mathrm{kWh}$ in 1991 to 6362.5 billion $\mathrm{kWh}$ in 2017, with an average annual growth rate of $14.32 \%$ [4].

China became the largest power generation country in the world in 2011, surpassing the United States [6]. And China also became the largest $\mathrm{CO}_{2}$ emitter in 2008 , since the $\mathrm{CO}_{2}$ emissions from China's electric power sector exceeded that of the U.S. for the first time (The Washington Post). Facing growing environmental pressure and the arduous task of reserving energy resources and reducing emissions, at the Copenhagen 2009 World Climate Conference the Chinese government made a commitment to reduce its carbon intensity by $40-45 \%$ relative to 2005 until the end of 2020 [7]. Moreover, China aims to peak the national $\mathrm{CO}_{2}$ emissions around 2030 and has promised to cut its carbon intensity by $60-65 \%$ in 2030 compared to 2005 at the United Nations Framework Convention on Climate Change (UNFCCC) Conference in 2015 [8]. Therefore, the power industry plays a pivotal role for the realization of China's commitment and international promise.

China entered a 'New Normal' economic development era in 2013, which means a high-quality and environmentally friendly economic growth mode [9]. The Chinese government put more emphasis on emission-reduction and resource-saving for future economic development. The ultimate purpose of the agreement in the Conference of Parties 21 (COP21) is how to reduce the $\mathrm{CO}_{2}$ emissions while maintaining a sustainable and satisfactory economy, or without damaging the pattern of economic development [10]. Under the 'New Normal Era' background, it is urgent for the Chinese government to pursue effective means or policies to ensure sustainable economic development by reducing energy use and $\mathrm{CO}_{2}$ emissions. As mentioned before, coal is the main fuel form for thermal power plant generation, which makes the power industry the major $\mathrm{CO}_{2}$ emissions sector. Therefore, studying the relationship between the power industry and the economy is the key issue in emissions-control and the 'New Normal' economy. The research motivations are obvious. The power industry, the backbone of China's continuous rapid economic development, contributes a large proportion of the $\mathrm{CO}_{2}$ emissions in China, so it is imperative to study the decoupling relationship between the power industry representative indicators (power generation $\mathrm{CO}_{2}$ emissions and electric carbon productivity) and economic development. It is significant to find effective means to reduce the emissions from the power industry without compromising the economy so as to achieve the coordination of the economy and the environment.

\section{Literature Review}

The past few decades have witnessed a plethora of studies that have investigated the decoupling between economic development and environment-related topics (like $\mathrm{CO}_{2}$ emissions or energy consumption). Some selected studies (after 2016) focused on multiple countries, such as: global [11], Organization for Economic Co-operation and Development (OECD) [12], Group of 20 (G20) [13], V4 countries (Czech Republic, Hungary, Poland and Slovakia) [14], etc. Reference [11] used OECD decoupling technique, Tapio elastic indicator and IGTX $^{1}$ Equation to evaluate the trend between world economic growth and the $\mathrm{CO}_{2}$ emissions. Reference [12] used the Tapio decoupling technique to explore the relationship between the emissions and the influential factors that were obtained through the logarithmic mean divisia index (LMDI) decomposition method. [13] took G20 as the research sample and and estimated the Environment Kuznets curve (EKC) and the causalities between the economy and energy and emissions in order to provide the decoupling strategy to cope with the environmental pressure. [14] applied the decoupling theory to the relationship evaluation between the emissions and the economy for the V4 countries from 1991 to 2012. Some scholars showed great interest in the decoupling status of the economy and environmental issues for a specific country, such as: Guevara and Domingos in Portugal [15], Wang and Wang in the United States [16], Roinioti and Koroneos in Greece [17], Freitas and Kaneko in Brazil [18], Wang and Jiang in China [19], Riti et al. in China [20], Lin and Wang et al. in China [21], and so on.

Among all the specific country decoupling research, there is a large proportion of study for China. This literature could be divided into three branches. The first branch is about the decoupling comparison between China and another country. Reference [22] compared

IGTX is a kind of equation in which I represents environmental pressure; $G$ represents the gross domestic product (GDP); T represents the amount of waste generation; and $X$ represents the discharge rate of waste. See reference: LU, Zhong-wu, YUE, Qiang. IeGTX Equation and IeGTe Equation: Analysis of $\mathrm{SO} 2$ and $\mathrm{COD}$ Emissions during Economic Growth in China. Research of Environmental Sciences, 23(9), 1101-1107, 2010. 
the decoupling performance by using the Tapio decoupling index between China and America, and the results showed that China experienced coupling or weak decoupling statues for most of the development period, while America experienced weak and strong decoupling. [23] compared the decoupling state between China and the U.S. by using a new two-dimensional decoupling model that could distinguish the different decoupling performances with different economic levels. [24] compared the coupling or decoupling status of economic output from energy requirements for China and India so as to make effort to achieve the emissionreduction goals.

The second branch focuses on a certain industry or sector. [25] measured the decoupling performance between the added value of the iron and steel industries and industrial carbon emissions by using the Tapio index for future sustainable development. [26] examined the decoupling relationship between China's construction output and the corresponding carbon emissions from this industry in order to pursue the sustainable lowcarbon development for the construction industry. [27] explored the decoupling between agricultural economic output and carbon emissions for 30 provinces by using the Tapio elasticity index during the period of 1997-2014, and found that fertilizer contributed the most emissions and should be added as a higher tax. [28] also used the Tapio decoupling model to examine the relationship between economic output and emissions from China's construction industry from national and provincial aspects. [29] employed the structural decomposition technique and Tapio index to evaluate the relationship between fossil fuel consumption and industrial output. [30] applied the Tapio indicator to explore the decoupling status between carbon emissions and output of the manufacturing industry for the period of 1995-2015. [31] used the decomposition and decoupling technique to test whether the decoupling status existed between economic development and carbon intensity for the commercial service industry from the national level and the top five urban agglomeration regions.

The third branch always takes the regions or provinces in China as the main research objects. [32] applied the LMDI decomposition technique to explore the influential indicators affecting emissions in all of China's regions and quantitatively analyzed the decoupling relationship between the regions' output and the carbon emissions through using the Tapio extended model. [33] combined EKC and the decoupling model to explore the interactions between Guangdong's economic output and the corresponding $\mathrm{CO}_{2}$ emissions so as to present referential low-carbon development policy for a certain province. [34] aimed at the aggregate and provincial regions and evaluated the decoupling extent between the emissions and real GDP using Kuznets elasticity. [35] explored the decoupling relationship between economic output and carbon intensity, per capita carbon emission and total emissions respectively by using the LMDI technique and the decoupling method. [36] compared the decoupling trend of the economy and carbon emissions between Beijing and Shanghai by using the Tapio elasticity index, and also applied the LMDI technique with decoupling indicator to find the main determining factors that affected the decoupling process for the industries of these two cities. [37] explored and analyzed the main driving indicators that affected the industrial emissions in Jiangsu by using complete decomposition and decoupling.

The aforementioned literatures provide the important theoretical foundation and stir some novel ideas for the following work. Actually, the Tapio technique is a feasible method to investigate the decoupling relationship between the economy and $\mathrm{CO}_{2}$ emissions from the power industry. Based on the above references review, the research literatures for China's industrial, regional, and provincial levels have been published extensively. Although the decoupling research in various forms and contents is abundant, to the best of our knowledge, studies concerning the decoupling exploration between economic and the power industryrelated indicators in China are limited, though the power industry is a key to achieving national lowcarbon goals. [38] mainly applied the Tapio model, the LMDI method and the Kaya identity equation to test the decoupling relationship between China's economy and the $\mathrm{CO}_{2}$ emissions from power industry and measured the influences of driving indicators on this decoupling relationship, while [39] applied the index decomposition technique to explore the electricity consumption driving indicators and then analyzed the decoupling status between the economy and the influential indicators in order to reveal the different driving effect to the decoupling in China. [40] used the dynamic panel data model for China's 100 prefecture-level cities to examine the decoupling relationship between economic growth and electrical power consumption and found that the decoupling statues differed across different regions. That is to say, few literatures have applied the decoupling technique to the power industry; and especially, there is no literature so far applying the decoupling index to research the relationship between the economy and two power industry-related indicators (i.e., $\mathrm{CO}_{2}$ emissions from the power industry and electric carbon productivity) from the aspect of the nation and provinces.

In all, on the basis of the above-mentioned study analysis, the contributions of this paper can be summarized in three aspects:

1) It is the first attempt to research the decoupling relationship between economic and power industryrelated indicators, i.e., power generation $\mathrm{CO}_{2}$ emissions and electric carbon productivity. Literally, the decoupling study between electric carbon productivity and the economy has not been seen so far.

2) The investigation on the relationship between the economy and $\mathrm{CO}_{2}$ emissions from power generation focuses not only on the nation but also on the 
provinces with different economic development levels. The aim is to find out the possible similarities and differences among these provinces and provide targeted policy suggestions for future low-carbon development.

3) From the study and application perspective, this paper is not confined to the analysis of a decoupling relationship between the economic and the power industry-related indicators, but studies in-depth the possible reasons behind the different decoupling statuses in order to find the potential and effective means and policies for emission reduction and low-carbon sustainable development for central and local governments to realize the coordinated development of the economy and the electric power industry.

\section{Material and Methods}

\section{Calculating Related Power Industry Indicators}

We selected power generation $\mathrm{CO}_{2}$ emissions and electric carbon productivity (ECP) to explore the connection between these indicators and economic output. Since the data of the $\mathrm{CO}_{2}$ emissions from power generation has not been published by Chinese official organizations, it is estimated by the product of the standard coal equivalent consumption from the power industry and its corresponding $\mathrm{CO}_{2}$ emissions coefficient, shown as Equation (1).

$$
C E_{t}=E G_{t} \times S F_{t} \times 2.6308
$$

...where $\mathrm{C} E_{t}$ represents the $\mathrm{CO}_{2}$ emissions from power generation side in the year of $t$ (unit: $10^{8}$ ton); $E G_{t}$ is the total power generation output in year of $t$ (unit: $10^{8} \mathrm{kWh}$ ), and $\mathrm{S} F_{t}$ is the standard coal consumption per $\mathrm{kWh}$ in $t$ year (unit: tce/kWh). The constant 2.6308 ton $\mathrm{CO}_{2} /$ tce in Equation (1) is the $\mathrm{CO}_{2}$ emission coefficient per unit of standard coal, which is recommended by the Energy Research Institute (ERI) of the National Development and Reform Commission (NDRC) [41].

Carbon productivity, advanced by Kaya and Yokobori [42], is an efficiency concept that means the ration of economic output to $\mathrm{CO}_{2}$ emissions. The electric carbon productivity could be defined as the amount of GDP from per unit $\mathrm{CO}_{2}$ emissions from the power industry according to the definition of carbon productivity, written as Equation (2):

$$
E C P=G / C E
$$

... where $E C P$ refers to electric carbon productivity; $G$ refers to economic output; and $C E$ represents the $\mathrm{CO}_{2}$ emissions for the power industry that could be obtained through Equation (1).

\section{Tapio Decoupling Index}

Decoupling, derived from the field of physics, made two or more physical quantities with response relationship irrelevant. Later, in order to analyze the relationship between economic growth and environmental pressure or resource consumption, the decoupling index was used widely due to its more specific concept and fewer calculations compared with EKC [43]. Nowadays, there are two general methods: the OECD decoupling index and the Tapio elasticity index. Even though these two methods are similar for measuring the decoupling degree, the algorithms for these two indices are different. In addition, the decoupling result obtained by the OECD index could be greatly influenced by the selection of the base year. The Tapio decoupling index could effectively avoid the limitation of the base selection, which can also improve the objectivity and accuracy of decoupling analysis. The Tapio index especially focuses on the variation between different years, which is conducive to testifying for the effectiveness of the policy implementation.

Since the Tapio decoupling index is more suitable for further decomposition, it is adopted in our work to verify the interrelationship between the indicators from the power industry (i.e., CE ECP) and GDP. Tapio decoupling elasticity index indicates the ratio of relative variation of environmental impacts and the relative variation of the economic output [44], shown as Equation (3):

$$
\varepsilon=\frac{\Delta E / E}{\Delta G / G}
$$

...where $\varepsilon$ represents the Tapio elasticity index; $E$ represents resource consumption or the waste emission amount; and $G$ represents the economic output for certain region. $\Delta E$ and $\Delta G$ represent the differences of $E$ and $G$ for a certain period of time, respectively.

According to the concept of Tapio index [45], the decoupling elasticity index between the power industryrelated indicators and GDP could be written as follows:

$$
\begin{gathered}
D_{1}=\frac{\Delta C E / C E_{0}}{\Delta G / G_{0}}=\frac{\left(C E_{t}-C E_{0}\right) / C E_{0}}{\left(G_{t}-G_{0}\right) / G_{0}} \\
D_{2}=\frac{\Delta E C P / E C P_{0}}{\Delta G / G_{0}}=\frac{\left(E C P_{t}-E C P_{0}\right) / E C P_{0}}{\left(G_{t}-G_{0}\right) / G_{0}}
\end{gathered}
$$

The subscripts ' 0 ' and ' $t$ ' in Equations (4) and (5) denote the base year and the target year. Therefore, in Equation (4), $C E_{t}$ and $G_{t}$ represent the national $\mathrm{CO}_{2}$ emissions from the power industry and GDP value in target year $t$, respectively; $C E_{0}$ and $G_{0}$ represent the $\mathrm{CO}_{2}$ emissions and GDP in base year 0, respectively; $\Delta G=G_{t}-G_{0}$ and $\Delta C E=C E_{t}-C E_{0}$ denote the difference of GDP and $\mathrm{CO}_{2}$ emissions in the research period $[0, t]$, 
respectively. Similarly, in Equation (5), $E C P_{t}$ and $E C P_{0}$ represent the electric carbon productivity in base and target years, respectively.

$D_{1}$ and $D_{2}$ stand for the decoupling level between CE and GDP, ECP and GDP, respectively.

\section{Data Sources}

Data in our work involve 30 provinces covering the research period of 2000-2016 (Tibet, Macao, Hong Kong and Taiwan are not considered due to the lack of data availability). The economic output data (in 2000 constant prices) are collected from the China Statistical Yearbook [46]. Data of $\mathrm{CO}_{2}$ emissions from the power industry (CE) could be calculated through Equation (1). Data of total power generation output and standard coal consumption per $\mathrm{kWh}$ are collected from China's Electric Power Statistical Yearbook [47]. And the electric carbon productivity (ECP) data could also be calculated by Equation (2). Table 1 shows the national data of CE, GDP and ECP.

Fig. 1 exhibits the line trend of annual GDP and the $\mathrm{CO}_{2}$ emissions from the power industry from 2000 to 2016, which shows a gradual rising feature. This means the rapid economic growth is accompanied by an increase of $\mathrm{CO}_{2}$ emissions from the power industry. And the growth rate of the economy is higher than that of $\mathrm{CO}_{2}$ emissions - especially after 2008. Fig. 2 exhibits the line trend of electric carbon productivity for the period 2000-2016, which also shows the increasing trend of the productivity. This indicates that the ratio of economic output to $\mathrm{CO}_{2}$ emissions increased gradually, which means more economic output per $\mathrm{CO}_{2}$ emission. It could be inferred that the growth trend results from the joint effect of high-quality economic development and carbon emissions control.

\section{Results and Discussion}

As the stochastic impacts might cause change to the Tapio index value, $\varepsilon \pm 20 \%$ variation of the elasticity

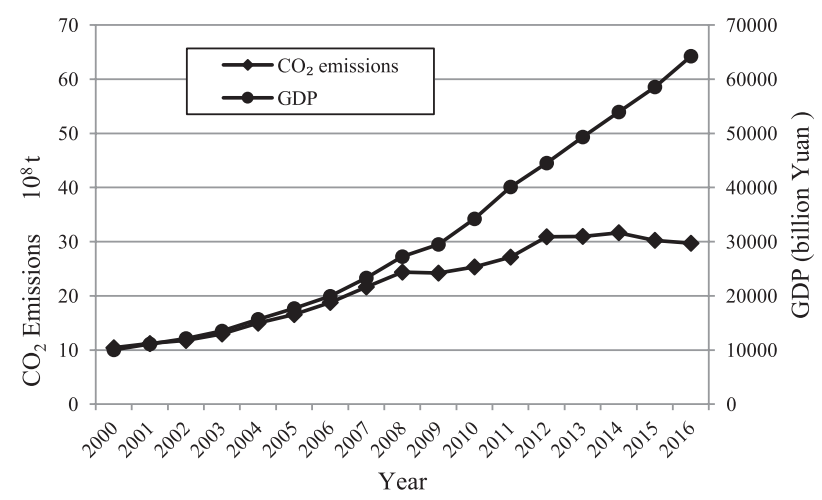

Fig. 1. Line trend chart for statistical data of annual $\mathrm{CO}_{2}$ emissions (Unit: $10^{8} \mathrm{t}$ ) and GDP (unit: billion yuan ) during 2000-2016.

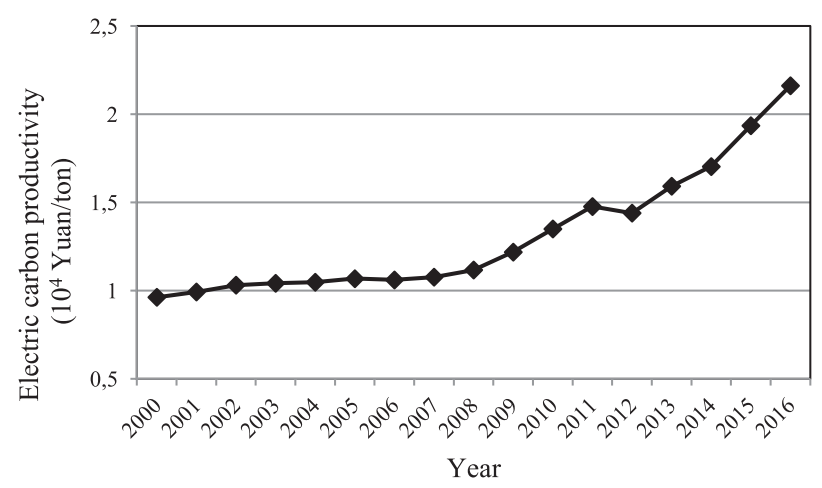

Fig. 2. Line trend chart for statistical data of the electric carbon productivity (unit: $10^{4}$ yuan/ton) during 2000-2016.

index value are still regarded as coupling in order to avoid over-interpreting minor changes as significant changes. In fact, more decoupling or coupling statuses would be introduced within the range of the interval value, resulting in possible chaotic decoupling states. Therefore, in our work the specific decoupling state would be discussed according to the status and national and provincial circumstances.

Table 1. Annual $\mathrm{CO}_{2}$ emissions (Unit: $10^{8} \mathrm{t}$ ), GDP (Unit: billion Yuan ) and the electric carbon productivity (unit: $10^{4}$ yuan/ton ) during 2000-2016.

\begin{tabular}{|c|c|c|c|c|c|c|c|c|c|}
\hline Year & 2000 & 2001 & 2002 & 2003 & 2004 & 2005 & 2006 & 2007 & 2008 \\
\hline $\mathrm{CO}_{2}$ Emissions & 10.4153 & 11.187 & 11.7563 & 12.9604 & 14.9556 & 16.544 & 18.7808 & 21.6386 & 24.3794 \\
\hline GDP & 10028.01 & 11106.78 & 12127.16 & 13505.16 & 15673.72 & 17669.00 & 19927.32 & 23303.01 & 27242.47 \\
\hline $\begin{array}{c}\text { Electric Carbon } \\
\text { Productivity }\end{array}$ & 0.9628 & 0.9928 & 1.0315 & 1.042 & 1.048 & 1.068 & 1.061 & 1.0769 & 1.1174 \\
\hline Year & 2009 & 2010 & 2011 & 2012 & 2013 & 2014 & 2015 & 2016 & \\
\hline $\mathrm{CO}_{2}$ Emissions & 24.2015 & 25.3417 & 27.1512 & 30.9119 & 30.9742 & 31.6606 & 30.2581 & 29.7146 & \\
\hline GDP & 29495.80 & 34216.28 & 40104.74 & 44513.07 & 49326.02 & 53941.93 & 58566.60 & 64248.52 & \\
\hline $\begin{array}{c}\text { Electric Carbon } \\
\text { Productivity }\end{array}$ & 1.2188 & 1.3502 & 1.4771 & 1.44 & 1.5925 & 1.7038 & 1.9356 & 2.1622 & \\
\hline
\end{tabular}


Table 2. Classification of the Tapio decoupling status.

\begin{tabular}{|c|c|c|c|c|}
\hline $\begin{array}{l}\text { Change of the power industry } \\
\text { related indicators } \triangle C E, \triangle E C P\end{array}$ & $\begin{array}{c}\text { Change of } \\
\text { economic output } \Delta \mathrm{G}\end{array}$ & $\begin{array}{l}\text { Decoupling } \\
\text { index }\end{array}$ & & Decoupling status \\
\hline$>0$ & $<0$ & $(-\infty, 0)$ & \multirow{3}{*}{$\begin{array}{l}\text { Negative } \\
\text { decoupling }\end{array}$} & Strong Negative Decoupling (SND) \\
\hline$<0$ & $<0$ & {$[0,0.8)$} & & Weak Negative Decoupling (WND) \\
\hline$>0$ & $>0$ & $(1.2,+\infty)$ & & Expansive Negative Decoupling (END) \\
\hline$<0$ & $>0$ & $(-\infty, 0)$ & \multirow{3}{*}{ Decoupling } & Strong Decoupling (SD) \\
\hline$>0$ & $>0$ & {$[0,0.8)$} & & Weak Decoupling (WD) \\
\hline$<0$ & $<0$ & $(1.2,+\infty)$ & & Recessive Decoupling (RD) \\
\hline$>0$ & $>0$ & {$[0.8,1.2]$} & \multirow{2}{*}{ Coupling } & Expansive Coupling (EC) \\
\hline$<0$ & $<0$ & {$[0.8,1.2]$} & & Recessive Coupling (RC) \\
\hline
\end{tabular}

\section{Decoupling Results and Analysis} at the National Level

According to Tapio decoupling theory, the decoupling status can be subdivided into three subcategories, namely decoupling (strong decoupling, weak decoupling, and recessive decoupling), coupling (expansive coupling, and recessive coupling), and negative decoupling (strong negative decoupling, weak negative decoupling, and expansive negative decoupling) [45], as seen in Table 2, which also shows that different decoupling index values indicate different decoupling statuses, which means that the decoupling relationship between the power industry-related indicators and GDP could be decoupled, coupled, or negatively decoupled.

As mentioned above, two decoupling aspects explore the decoupling relationship between economic output and power industry-related indicators, namely between CE and GDP, ECP and GDP. Tables 3 and 4 show the decoupling status between $\mathrm{CE}$ and GDP, and ECP and GDP, respectively. In order to show the clear and intuitive display of different decoupling status, the decoupling results are drawn in Figs 3 and 4, respectively. Generally speaking, the decoupling relationship shows obvious periodic characteristics. Among eight decoupling statuses, there are only four statuses appearing in this issue, i.e., $\mathrm{END}, \mathrm{WD}, \mathrm{SD}$, and EC.

Table 3 and Fig. 3 depict the decoupling trends between CE and GDP from 2000 to 2016. For the periods of 2000-2002 and 2006-2016, there was a relatively long decoupling. For most research periods, WD existed, and the target SD status appeared during the period of 2008-2009, and 2014-2016; however, the unfavorable END status existed from 2011to 2012. During period of the WD status, which is also called 'relative decoupling', both CE and GDP increased, but the economic output growth rate is much higher than that of CE.

When CE decreases with the growth of GDP, it shows the absolute decoupling-SD. During the research periods 2008-2009 and 2014-2016, the target SD status exhibited. The reasons are explained as follows. In 2008, the Olympic Games held in Beijing fostered China's economic growth and brought new economic points through attracting more business and investors to China. During this period, the Chinese government enhanced the standard of energy-saving and emissionreduction, and encouraged the use of green energy (solar, wind, and geothermal) over fossil-fuels, and reducing the power demand generated from the thermal power plants so as to keep the sky blue and clouds white. During 2014-2016, the SD state between CE and the economy is mainly the result of a combination of the 'New Normal' economic development phase and the deeper reform and development in electric power industry. The 'New Normal' economy aims at the green and high-quality economic development model while controlling emissions at the same time, with the purpose of coordinating the economy and the environment. In addition, the new round reform in electric power industry in March 2015, which is guided by 'No. 9 Document' issued by the Chinese government, carried out a series of policies like pricing bidding, full utilization of renewable energy generation, etc. This can effectively solve power system planning and especially promote the sufficient use of renewable energy resources to encourage participation in the electric market and substitute part of coal-fired power plants, resulting in fewer emissions from the power generation side.

From 2011 to 2012, the decoupling status showed END state, which means that the growth rate of CE $(13.85 \%)$ was much higher than that of the economy (10.99\%). Possible reasons might result from the leakage of Japan's Fukushima nuclear power plant due to the earthquake and tsunami. Considering the nuclear safety problem, the Chinese government suspended approval for new nuclear power projects and announced a moratorium on building nuclear power plants in inland provinces [47]. Therefore, thermal power plants were allowed to generate more electricity to fill the demand gap, resulting in more $\mathrm{CO}_{2}$ emissions from the thermal power plants and higher growth rate of the emissions. 
Table 3. Decoupling results between CE and GDP from 2000 to 2016.

\begin{tabular}{|c|c|c|c|c|c|c|c|c|}
\hline Period & $2000-2001$ & $2001-2002$ & $2002-2003$ & $2003-2004$ & $2004-2005$ & $2005-2006$ & $2006-2007$ & $2007-2008$ \\
\hline$\Delta C E / C E_{0}$ & 0.0741 & 0.0509 & 0.1024 & 0.1539 & 0.1062 & 0.1352 & 0.1522 & 0.1267 \\
\hline$\Delta G / G_{0}$ & 0.1076 & 0.0919 & 0.1136 & 0.1606 & 0.1273 & 0.1278 & 0.1694 & 0.1691 \\
\hline Tapio & 0.6888 & 0.5539 & 0.9014 & 0.9587 & 0.8343 & 1.0578 & 0.8983 & 0.7492 \\
\hline Decoupling status & WD & WD & EC & EC & EC & EC & WD & WD \\
\hline Period & $2008-2009$ & $2009-2010$ & $2010-2011$ & $2011-2012$ & $2012-2013$ & $2013-2014$ & $2014-2015$ & $2015-2016$ \\
\hline$\Delta C E / C E_{0}$ & -0.0073 & 0.0471 & 0.0714 & 0.1385 & 0.002 & 0.0222 & -0.0443 & -0.018 \\
\hline$\Delta G / G_{0}$ & 0.0827 & 0.16 & 0.1721 & 0.1099 & 0.1081 & 0.0936 & 0.0857 & 0.097 \\
\hline Tapio & -0.0882 & 0.2944 & 0.4149 & 1.2601 & 0.0186 & 0.2368 & -0.5167 & -0.1851 \\
\hline Decoupling status & SD & WD & WD & END & WD & WD & SD & SD \\
\hline
\end{tabular}

The decoupling status exhibited EC for the period of 2002-2006. The possible reasons are as follows. Effected by the Asian financial crisis from 1997 to 1998, the global and regional economy was influenced significantly. The economic growth rate in China is $7.84 \%$ and $7.77 \%$ (at 1990 constant price) for 1997-1998 and 1998-1999, respectively. After recovering from the financial crisis, China showed rapid economic development with average annual growth rate of $11.07 \%$ from 2002 to 2006. Quick economic development is based on a large amount of fossil energy and electricity generated by thermal power plants, inevitably causing a great deal of $\mathrm{CO}_{2}$ emissions without facing tremendous emissions reduction and environmental pressure. Therefore, the relationship between $\mathrm{CE}$ and the economy showed obvious EC status.

Based on the analysis of the relationship between $\mathrm{CO}_{2}$ emissions from the power industry and GDP, it could first be inferred that the general trend changed from coupling status to decoupling status. However, the

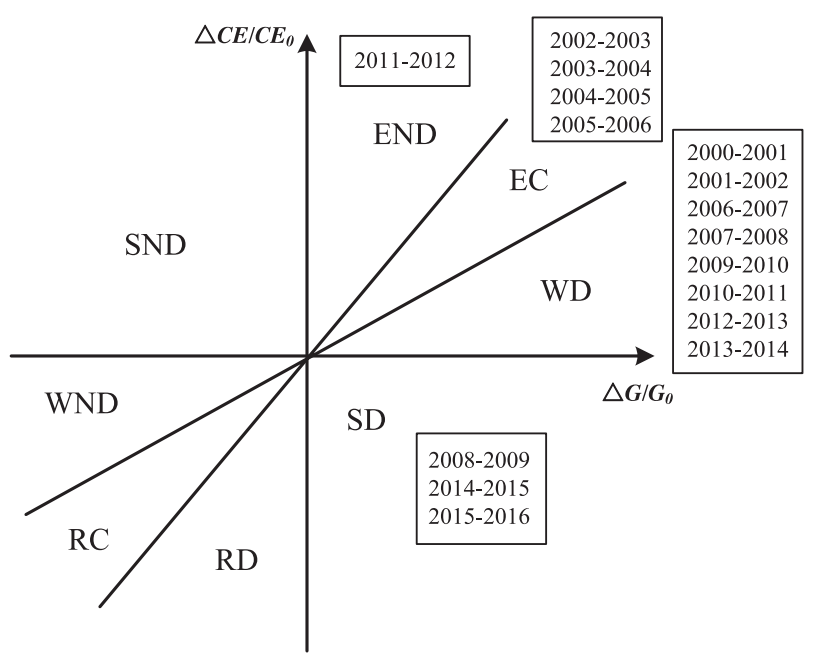

Fig. 3. Decoupling status between CE and GDP from 2000 to 2016. dependence of the economy on $\mathrm{CO}_{2}$ emissions from the power industry was still obvious. Therefore, more strict emissions control measures should be implemented so as to decrease emissions while keeping steady electricity generation to guarantee economic development. Second, the decoupling status could be affected by policies, economic events, and political events such as: the 'No. 9 Document' and the Asian financial crisis mentioned above, and so on. Consequently, the national policies and planned goals proposed by the Chinese central government are effective ways to realize the low-carbon development of the economy and power industry.

Table 4 and Fig. 4 depict the decoupling relationship between ECP and GDP for the research period 2000-2016. This relationship experienced different decoupling states, including SD, WD, EC and END. During 2000-2005, 2006-2008, 2009-2011, and 2013-2014, the decoupling status showed WD status. EC status was exhibited for 2008-2009 and 2012-2013. The period of 2004-2006 showed END status. Different from the decoupling relationship between $\mathrm{CE}$ and economic output, the decoupling between ECP and GDP has opposite meanings. The common characteristics for WD, END and EC are that ECP is increasing while the GDP is increasing too, which means that ECP can be improved and that $\mathrm{CO}_{2}$ reduction can be achieved without sacrificing economic growth. These three kinds of decoupling status are satisfactory, especially the END status that means that the increased speed of ECP is higher than that of GDP. Only the SD status is not acceptable because with the increasing of GDP, ECP showed a downward trend. SD status appeared for the periods of 2005-2006 and 2011-2012. The possible reasons are as follows. Since joining the World Trade Organization, China has achieved booming economic performance, which is the main focus for Chinese national policy. This resulted in higher energy and electricity demand, thus the corresponding $\mathrm{CO}_{2}$ emissions, surpassing the growth rate of GDP. Therefore, ECP, which is the rationing of GDP to $\mathrm{CO}_{2}$ emissions from the power industry, decreased obviously 
Table 4. Decoupling results between ECP and GDP from 2000 to 2016.

\begin{tabular}{|c|c|c|c|c|c|c|c|c|}
\hline Period & $2000-2001$ & $2001-2002$ & $2002-2003$ & $2003-2004$ & $2004-2005$ & $2005-2006$ & $2006-2007$ & $2007-2008$ \\
\hline$\Delta E C P / E C P_{0}$ & 0.0312 & 0.039 & 0.0102 & 0.0058 & 0.0191 & -0.0066 & 0.015 & 0.0376 \\
\hline$\Delta G / G_{0}$ & 0.1076 & 0.0919 & 0.1136 & 0.1606 & 0.1273 & 0.1278 & 0.1694 & 0.1691 \\
\hline Tapio & 0.2896 & 0.4243 & 0.0896 & 0.0359 & 0.1499 & -0.0513 & 0.0885 & 0.2225 \\
\hline Decoupling status & WD & WD & WD & WD & WD & SD & WD & WD \\
\hline Period & $2008-2009$ & $2009-2010$ & $2010-2011$ & $2011-2012$ & $2012-2013$ & $2013-2014$ & $2014-2015$ & $2015-2016$ \\
\hline$\Delta E C P / E C P_{0}$ & 0.0907 & 0.1078 & 0.094 & -0.0251 & 0.1059 & 0.0699 & 0.136 & 0.1171 \\
\hline$\Delta G / G_{0}$ & 0.0827 & 0.16 & 0.1721 & 0.1099 & 0.1081 & 0.0936 & 0.0857 & 0.097 \\
\hline Tapio & 1.0971 & 0.6737 & 0.5461 & -0.2285 & 0.9795 & 0.7469 & 1.5869 & 1.2067 \\
\hline Decoupling status & EC & WD & WD & SD & EC & WD & END & END \\
\hline
\end{tabular}

during the period 2005-2006. SD status for the period of 2011-2012 is different, which could be explained by the unusual change of non-fossil fuel electricity generation. In order to fight air pollution and climate change, the Chinese government has been exerting great effort to develop non-fossil fuel energy generation, like hydropower generation, nuclear generation, wind power generation, etc. However, the growth rate for the period of 2011-2012 showed an unforeseen low trend at $0.47 \%$. The mains reasons involve the unprecedented drought and unexpected leakage in Fukushima nuclear plant in 2011, which impeded the electricity generation amount of hydropower plants and the installed capacity growth in a nuclear plant. It trigged more electricity being generated by thermal power plants, with greatly increased $\mathrm{CO}_{2}$ emissions. ECP obviously decreased compared with the previous year, resulting in negative relative growth rate. Therefore, the relationship showed SD status for the period of 2011-2012.

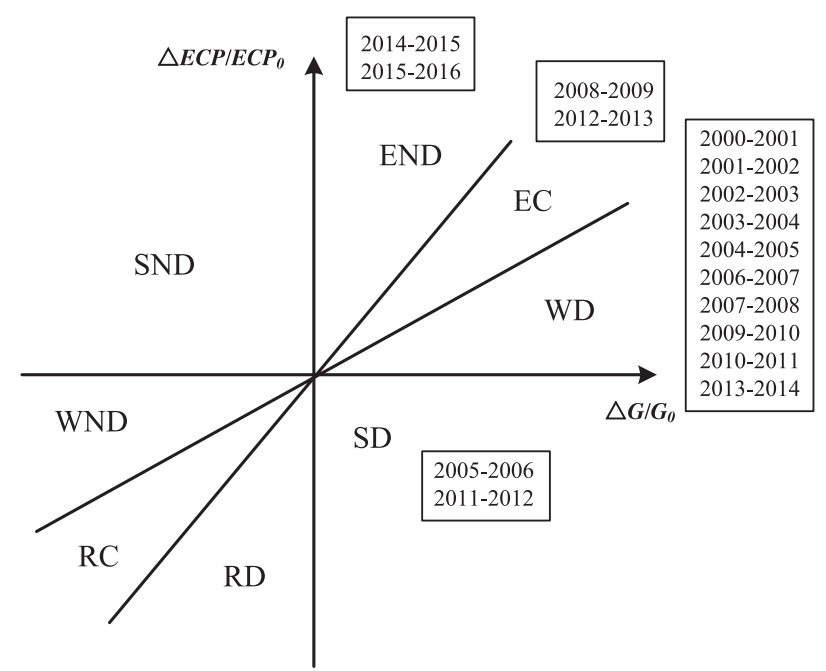

Fig. 4. Decoupling status between ECP and GDP from 2000 to 2016.

\section{Decoupling Results and Analysis on Regional Level}

\section{Three Time Phases Analysis from Provincial Aspect}

The five-year plans (FYP) are a set of development initiatives for the Chinese government to adjust growth targets and offer policy guidelines. In past decades, the FYP development mode has been implemented to map out China's strategies for growth in a five-year period. In accordance with the Chinese FYP, each FYP includes a five-year period, for example the first year of the $10^{\text {th }}$ FYP begins in 2001 and ends in 2005. In order to analyze conveniently, the year 2000 is included in the $10^{\text {th }}$ five-year plan, and the $12^{\text {th }}$ five-year plan includes 2016. Therefore, the research period (2000-2016) in our work is divided into three time phases: the $10 \mathrm{t}^{\mathrm{h}}, 11^{\mathrm{th}}$, and $12^{\text {th }}$ FYP research periods.

Using the Tapio decoupling index, the decoupling results between $\mathrm{CE}$ and GDP are uncovered from provincial level in this part. The calculation results

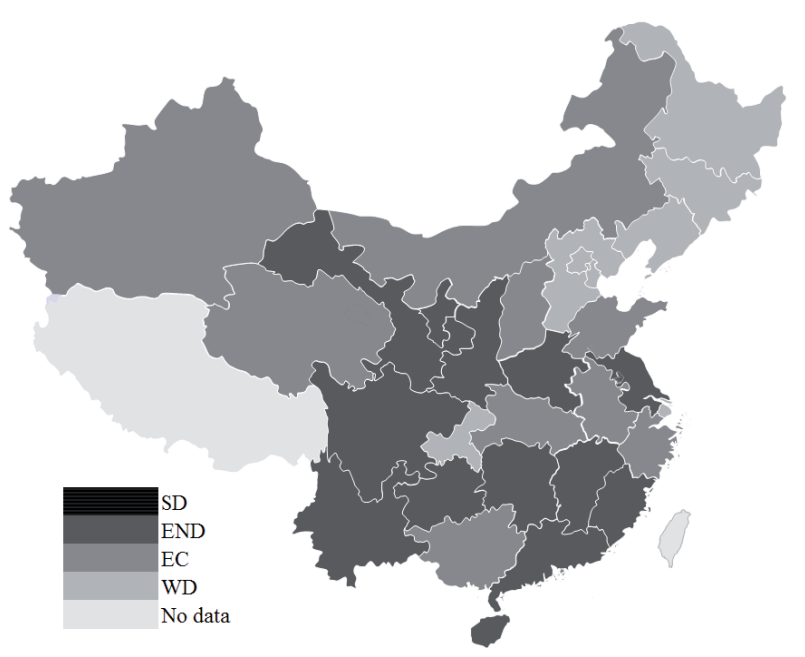

Fig. 5. Decoupling statuses for 30 provinces during 2000-2005 $\left(10^{\text {th }} \mathrm{FYP}\right)$. 
Table 5. Decoupling statuses of 30 provinces for three time phases.

\begin{tabular}{|c|c|c|c|c|c|c|c|}
\hline NO & Province & $2000-2005$ & Status & 2006-2011 & Status & $2012-2016$ & Status \\
\hline 1 & Beijing & 0.6156 & WD & 0.2059 & WD & 0.7411 & WD \\
\hline 2 & Tianjin & 0.7113 & WD & 0.5595 & WD & -0.1928 & SD \\
\hline 3 & Hebei & 0.7357 & WD & 0.5177 & WD & -0.0553 & SD \\
\hline 4 & Shanxi & 1.1827 & $\mathrm{EC}$ & 0.5824 & WD & -0.1257 & SD \\
\hline 5 & Inner Mongolia Mongolia & 0.9301 & $\mathrm{EC}$ & 0.7013 & WD & 0.2872 & WD \\
\hline 6 & Liaoning & 0.4634 & WD & 0.2358 & WD & -0.0878 & $\mathrm{SD}$ \\
\hline 7 & Jilin & 0.5126 & WD & 0.2491 & WD & -0.1651 & SD \\
\hline 8 & Heilongjiang & 0.5566 & WD & 0.1034 & WD & -0.0648 & $\mathrm{SD}$ \\
\hline 9 & Shanghai & 0.3854 & WD & 0.4375 & WD & -0.5341 & $\mathrm{SD}$ \\
\hline 10 & Jiangsu & 1.3491 & END & 0.3143 & WD & 0.2378 & WD \\
\hline 11 & Zhejiang & 1.1432 & $\mathrm{EC}$ & 0.6280 & WD & -0.0566 & SD \\
\hline 12 & Anhui & 1.1541 & $\mathrm{EC}$ & 1.2213 & END & 0.4754 & WD \\
\hline 13 & Fujian & 1.8616 & END & 0.6937 & WD & -0.5046 & SD \\
\hline 14 & Jiangxi & 1.2030 & END & 0.5903 & WD & 0.4331 & WD \\
\hline 15 & Shandong & 0.9434 & $\mathrm{EC}$ & 0.3207 & WD & 0.8546 & $\mathrm{EC}$ \\
\hline 16 & Henan & 1.2188 & END & 0.4679 & WD & -0.0660 & SD \\
\hline 17 & Hubei & 0.9757 & $\mathrm{EC}$ & 0.4179 & WD & 0.1484 & WD \\
\hline 18 & Hunan & 1.9723 & END & 0.5926 & WD & -0.3934 & $\mathrm{SD}$ \\
\hline 19 & Guangdong & 0.7089 & END & 0.4181 & WD & -0.2491 & $\mathrm{SD}$ \\
\hline 20 & Guangxi & 1.1428 & $\mathrm{EC}$ & 1.1295 & $\mathrm{EC}$ & -0.2635 & SD \\
\hline 21 & Hainan & 2.0433 & END & 0.9927 & $\mathrm{EC}$ & 0.3075 & WD \\
\hline 22 & Chongqing & 0.5695 & WD & 0.3731 & WD & 0.0093 & WD \\
\hline 23 & Sichuan & 1.2414 & END & 0.1385 & WD & -0.8234 & $\mathrm{SD}$ \\
\hline 24 & Guizhou & 2.4045 & END & 0.2675 & WD & 0.1654 & WD \\
\hline 25 & Yunnan & 2.7000 & END & 0.4583 & WD & -0.9425 & $\mathrm{SD}$ \\
\hline 26 & Shaanxi & 1.2710 & END & 0.8139 & $\mathrm{EC}$ & 0.3544 & WD \\
\hline 27 & Gansu & 1.7363 & END & 1.0237 & $\mathrm{EC}$ & -0.1173 & SD \\
\hline 28 & Qinghai & 1.0845 & $\mathrm{EC}$ & 0.4878 & WD & 0.3568 & WD \\
\hline 29 & Ningxia & 1.7229 & END & 0.7218 & WD & -0.0330 & $\mathrm{SD}$ \\
\hline 30 & Xinjiang & 1.1572 & $\mathrm{EC}$ & 1.1907 & $\mathrm{EC}$ & 2.4610 & END \\
\hline
\end{tabular}

are listed in Table 5. The decoupling statuses of the 30 provinces during three time phases are shown in Figs 5-7, respectively.

Fig. 5 shows that eight provinces displayed WD, which means that $\mathrm{CE}$ decreased with the increasing economic output, and the increased speed of CE is lower than that of economic output. Nine provinces showed an EC relationship, which indicates that the $\mathrm{CE}$ increases when GDP increases, and that the decoupling elasticity is between 0.8 and 1.2. The unsatisfied END status was found in 13 provinces, which means that the growth trend of CE was much more obvious than that of GDP.
During the period of $10^{\text {th }} \mathrm{FYP}$, there were only eight provinces in WD status, and most provinces showed EC or END status. This indicates that during the $10^{\text {th }}$ FYP, the main purpose is to develop the economy, and environmental pressure is limited. Many provinces consume more energy, especially electricity to pursue high-speed economic development. At the same time, the installed capacity for power generation has increased from $23754.02 \times 10^{4} \mathrm{~kW}$ in 2000 to $49736.51 \times 10^{4} \mathrm{~kW}$ in 2005 , with an average annual growth rate of $21.87 \%$. Generation from thermal power plants reached 1107.94 billion $\mathrm{kWh} \mathrm{n} 2000$ and 2017.93 billion $\mathrm{kWh}$ 


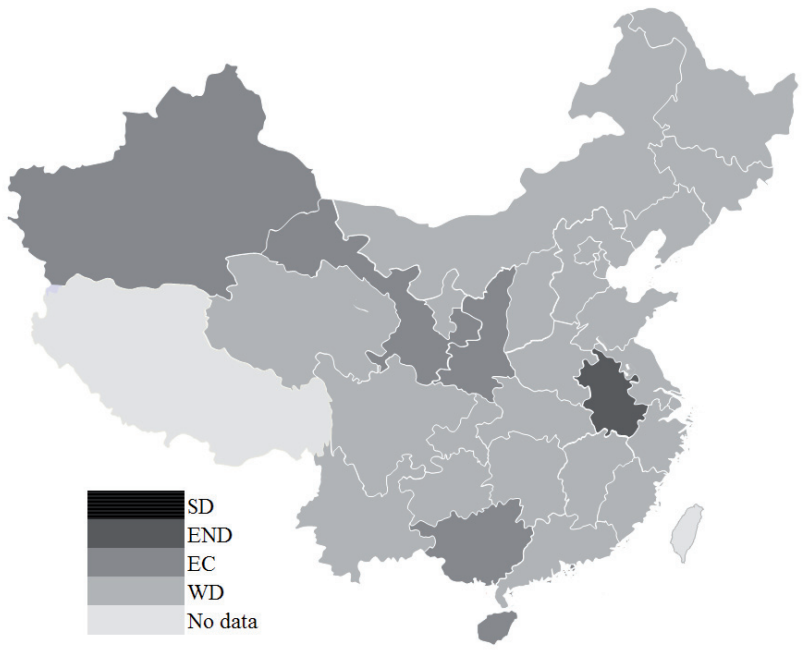

Fig. 6. Decoupling statuses for 30 provinces during 2006-2010 (11 $1^{\text {th }}$ FYP).

in 2005 , contributing to $80.96 \%$ and $81.54 \%$ of the national total generation, respectively. $\mathrm{CO}_{2}$ emissions from the power industry increased from $10.4153 \times 10^{8}$ ton to $16.544 \times 10^{8}$ ton. The effective emission-reduction policies should be implemented fully, such as: other generation options with lower emissions, improving the generation efficiency of the thermal power plants, and so on.

As shown in Fig. 6, during the $11^{\text {th }}$ FYP period the relationship between $\mathrm{CE}$ and economic output presented WD status in the majority of 30 provinces except for Anhui, Guangxi, Hainan, Shannxi, Gansu, and Xinjiang. These results suggested that the main feature of this period was the relatively lower growth speed of CE with higher economic growth speed. The GDP has increased from 19637.67 billion yuan in 2006 to 31829.89 billion yuan in 2010 (2000 constant price), with an average annual growth rate of $12.84 \%$. Although the economic crisis resulted from the American subprime mortgage crisis and the European debt crisis occurred in 2008, the Chinese economy still grew. The annual growth rate of the economy for the period of $2008-2009$ is about $11.66 \%$, without any obvious decline trend compared with other periods (14.64\% for the period of $2006-2007,11.95 \%$ for the period of 2007-2008, and $12.84 \%$ for the period of 2009 2010). At the same time, the growth rate of CE stepped down significantly, with an average annual growth rate of $7.97 \%$. Therefore, the increased speed of CE is lower than that of GDP, which shows WD status. On the one hand, the Chinese government has announced a goal of $20 \%$ reduction of energy intensity below 2005 levels by 2020, and the total target was allocated to the provinces. Therefore, all the provinces paid more attention to high-quality economic development while controlling the energy consumption and $\mathrm{CO}_{2}$ emissions. On the other hand, in the outline of the $11^{\text {th }}$ FYP for national economic and social development, the development policy for the power industry involves the energy efficiency improvement, ecological environment protection, the new energy generation encouragement, and so on. Therefore, the power industry has implemented a series of programs to enhance the generation efficiency of thermal power plants and improve the proportion of renewable energy generation to echo the national energy intensity reduction target. Speeding up the shutdown of small thermal power units is an important measure for improving the generation efficiency and achieving energy-conservation and emission-reduction goals of the power industry. The NDRC endorsed a plan in 2007 to close the small 50 gigawatt $(\mathrm{GW})$ inefficient fossil-fuel power plants by 2020 , accounting for $8 \%$ of total generation capacity. The newly built generation sets were all high-parameter and large-capacity units, especially constructing the supercritical units and the ultra-supercritical units. In addition, the Chinese government issued a series of plans, such as: 'Renewable energy law of the People's Republic of China' in 2006, 'Medium- and long-term plan for renewable energy development' in 2007 [48], and 'Medium- and long-term plan for nuclear energy development (2005-2020)' in 2007 [49] to stir renewable energy generation, encourage safe and efficient nuclear power, develop clean and efficient coal power, and so on. Taking wind power as an example, since 2005 China's wind power industry has made dramatic progress. The installed capacity increased from $2.07 \mathrm{GW}$ in 2006 to $44.73 \mathrm{GW}$ in 2010 , with an average annual growth rate of more than $104 \%$ during the period of the $11^{\text {th }}$ FYP [50]. According to the 'Mediumand long-term plan for nuclear energy development (2005-2020)', the proportion of nuclear power installed capacity will increase to $4 \%$, reaching 40 million $\mathrm{kW}$ by 2020 . The above measures are effective in reducing emissions from the power generation side, resulting in lower growth speed of CE and WD status for most provinces.

Fig. 7 shows that during the $12^{\text {th }}$ FYP period, almost all the provinces showed SD or WD status, except for Shandong and Xinjiang, after the quality-based economic development and emissions control in the power industry. As mentioned above, since 2013 China's economy has entered the 'New Normal' development phase, which is different from high-speed economic growth, large-amount energy consumption and high $\mathrm{CO}_{2}$ emissions. The Chinese government encourages all the provinces to pursue sustainable economic development that features mid- to high-speed growth with high productivity and lower-emission characteristics. During this period, China also experienced the fastest growing market for renewable energy utilization, except for nuclear because of the safety issue. The $12^{\text {th }}$ FYP Power Development Plan, published in 2010, readjusted the ambitious targets for the installed capacities of wind, solar PV and biomass energy with $100 \mathrm{GW}$, $21 \mathrm{GW}$ and $13 \mathrm{GW}$ for 2020 in order to achieve the $14 \%$ non-fossil share in primary energy by 2015 compared 


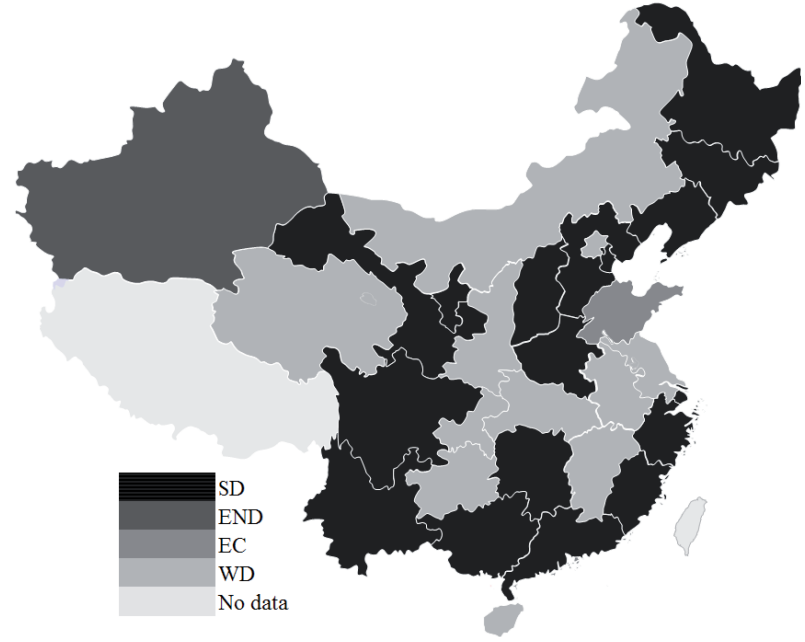

Fig. 7. Decoupling statuses for 30 provinces during 2011-2016 $\left(12^{\text {th }}\right.$ FYP $)$.

to 2010 [51]. In addition, in 2015 the 'Further strengthening reform of power industry', usually called Document 9, was issued by the Communist Party of China and State Council, mainly including the establishment of a price bidding mechanism, new power system planning mechanism and new policies about renewable energy generation. Price bidding is a more effective means to give priority dispatch to renewable energy generation, whose utilization would be enhanced from provincial and trans-provincial aspects. These measures are an active response to the national policy on improving the renewable energy share and cleanefficiency coal power, which can effectively control emissions from the power industry.

The decoupling analysis of three five-year time phases was carried out in this sector, and the provincebased decoupling analysis, including certain typical provinces shown in a different five-year period, would be discussed next.

Based on the time-phase analysis of the decoupling relationship from provincial aspect, it could be summarized that: (1) during the $11^{\text {th }}$ FYP period, most provinces showed expansive coupling or expansive negative decoupling status, which means that almost all the provinces aimed at economic development without paying more attention to the environment; (2) during the $12^{\text {th }}$ FYP, most provinces showed weak decoupling status except for several regions, which means that the increased speed of emissions was lower than that of the economy, strongly supporting the effect of policies from the Chinese power industry, such as: developing the renewable energy generation, closing small-inefficient plants; (3) during the $13^{\text {th }}$ FYP, most provinces showed satisfactory strong decoupling status or weak decoupling status, which is the combined effect of the 'New Normal' economic model and the new electric power system reform implementation.
Regional Decoupling Status Evolution Analysis

This section discusses the decoupling status evolution from the provincial aspect. For easy comparison, 30 provinces were divided into three groups according to the similarity of decoupling status evolution.

In group I, the decoupling status of Shanghai and Tianjin changed from WD status in the $10^{\text {th }} \mathrm{FYP}$ to SD status in the $12^{\text {th }} \mathrm{FYP}$, indicating that these two provinces have made effective measures to realize the quality-production rather than just speed-development mode and to control the emissions from power industry obviously. The decoupling elasticity of Shanghai is $0.3854,0.4375$, and -0.5341 for the $10^{\text {th }}, 11^{\text {th }}$, and $12^{\text {th }}$ five-year periods, respectively. The elasticity of Tianjin is $0.7113,0.5595$, and -0.1928 for the same period. Taking Shanghai as an example, Shanghai was listed as a low-carbon pilot city, and the local government has taken a series of policies to support the low-carbon development in the power industry. The power system plays a supportive role in Shanghai's economy, which covers many kinds of renewable or clean energy generation forms, such as biomass, waste, wind, and solar energy. Beijing and Chongqing showed WD status for the whole research period, but the decoupling elasticity showed a different trend for these two provinces. The decoupling elasticity of Beijing is $0.6156,0.2059$, and 0.7411 for the $10^{\text {th }}, 11^{\text {th }}$, and $12^{\text {th }}$ fiveyear periods, respectively, showing the fluctuation trend, while the elasticity of Chongqing is $0.5695,0.3731$, and 0.0093 for the same period, showing an obvious decline trend. For Beijing, the decoupling elasticity is 0.7411 in the $12^{\text {th }}$ FYP, which is much higher than that of the $11^{\text {th }}$. During the $12^{\text {th }} \mathrm{FYP}$, the cumulative growth rate of CE was $31.20 \%$ compared with $10.67 \%$ in the $11^{\text {th }}$ FYP, showing rebound characteristic in Beijing, while the cumulative growth rate of the economy was $42.10 \%$ in the $12^{\text {th }}$ FYP, compared with $51.85 \%$ in the 11 th FYP, showing a continuous slowdown trend. Abnormally, the annual growth rate of CE was $16.08 \%$ in Beijing for the period 2012-2013. From the Electric Power Statistical Yearbook, the total power generation increased from 29.3 billion $\mathrm{kWh}$ in 2012 to 33.6 billion in 2013, with annual growth rate of $14.68 \%$, while the power generation from the thermal power plants increased from 28.3 billion $\mathrm{kWh}$ in 2012 to 32.9 billion in 2013, with an annual growth rate of $16.25 \%$. In addition, the proportion of the thermal power generation was $96.59 \%$ in 2012 and $92.92 \%$ in 2013 , which resulted in the unusual rebound of $\mathrm{CO}_{2}$ emissions from the Beijing power industry, and thus higher decoupling elasticity. The common characteristic of Hebei, Liaoning, Jilin, Heilongjiang was that the decoupling status for these provinces changed from WD status in the 10th and the 11th FYP to SD status in the $12^{\text {th }}$ FYP. For example, the decoupling elasticity of Hebei province was 0.7357 , 0.5177 and -0.0553 for 2000-2005, 2006-2010, and 2011-2016. The decoupling elasticity of these provinces 
decreased from a positive value to a negative value during the research period. After the transformation of economic development mode and the emissions control for the local power industry, these three provinces realized that economic growth was accompanied by the decrease of emissions.

In group II, the relationship between CE and GDP for most provinces (including Shanxi, Inner Mongolia, Zhejiang, Hubei, Guangxi, and Qinghai) was similar, presenting an overall trend of EC to WD or SD transformation. The main features of these provinces in the 10th FYP was high economic output and high emissions from power generation to support the provincial development, showing manifest EC status. Through the development and reform for two FYPs, these provinces showed ideal target status in the $12^{\text {th }}$ FYP, which means that the CE decreased when GDP increased. This also indicated the overall effect of economic development mode transformation and lowcarbon achievement in the local power industry. But three provinces - Anhui, Shandong and Xinjiang showed different decoupling status. Anhui provinces showed EC, END, and WD during this research period. Anhui was a typical medium-speed economic development province with high energy consumption especially of electricity. The high proportion installed capacity of thermal power plants was $98.02 \%$ in 2000 , decreasing to $94.76 \%$ in 2016 . Correspondingly, the proportion of thermal power generation to the provincial total generation was $93.74 \%$ in 2000 , decreasing to $85.73 \%$ in 2016. Especially the 'East Anhui power transmission' project, which has been constructed since 2007, pulled up the thermal power generation obviously. All this contributed to the dramatic increase of $\mathrm{CO}_{2}$ emissions from power generation, resulting in the unsatisfied decoupling status. Shandong showed EC, WD, and EC during the same period. The decoupling elasticity was $0.9434,0.3207$, and 0.8546 for the three time phases, respectively. During the $11^{\text {th }}$ FYP, the growth rate of CE was $19.60 \%$, which was much lower than that of the economy with $61.13 \%$, resulting in WD status. But for most of the research period, the growth rate of $\mathrm{CE}$ was similar to that of the economy, which made Shandong EC status for the $10^{\text {th }}$ and the $12^{\text {th }}$ FYPs. Different from Anhui, Shandong is a typical province with high economic output and high emissions. As one of the large economic provinces, the local GDP in Shandong ranks third in China, with a contribution of $6.89 \%$ to the national total GDP in 2017. At the same time Shandong is also a huge resource consumption region. In 2000, the installed capacity of thermal power plants was $1992.60 \times 10^{4} \mathrm{~kW}$, accounting for $99.58 \%$ of the provincial total installed capacity, and the thermal power generation reached $1000.541 \times 10^{8} \mathrm{kWh}$, with a proportion of $99.97 \%$ to total generation. In 2016, the installed capacity and generation amount of the thermal power plants reached $9540 \times 10^{4} \mathrm{~kW}$ and $4671 \times 10^{8} \mathrm{kWh}$, accounting for $87.19 \%$ and $96.05 \%$, respectively. The high proportion of installed capacity and generation of thermal power plants is the main reason for high $\mathrm{CO}_{2}$ from the power industry. Xinjiang showed EC, EC, and END during the $10^{\text {th }}, 11^{\text {th }}$, and $12^{\text {th }}$ FYPs. The decoupling elasticity of the research period is greater than 1, showing a definite correlation between GDP and $\mathrm{CE}$. Xinjiang is not a huge economic region, whose GDP accounts for approximately $1 \%$ of the national total economy. But, Xinjiang is a typical energy-supported (especially electricity) province. The heavily industrialdominated economic structure and coal-dependent generation form exacerbated the environmental pressure along with economic development. In Xinjiang, the proportion of coal-based thermal plants installation capacity and power generation was over $80 \%$. In addition, the 'Xinjiang outward power transmission' project encouraged transferring the local coal resources into electricity to transmit to other provinces. These measures made a huge contribution to emissions from the power industry.

In group III, the decoupling status for Jiangsu, Fujian, Jiangxi, Henan, Hunan, Guangdong, Sichuan, Guizhou, Yunnan, Ningxia showed END in the $10^{\text {th }}$ FYP, and changed to WD in the $11^{\text {th }} \mathrm{FYP}$, and finally displayed ideal SD status or WD (only Jiangsu, Jiangxi and Guizhou) in the $12^{\text {th }} \mathrm{FYP}$, while, three provinces (Hainan, Shaanxi and Gansu) showed different status. The decoupling elasticity of these three provinces was $2.0433,1.2710$, and 1.7363 during the $10^{\text {th }}$ FYP; 0.9927, 0.8139 , and 1.0237 during the $11^{\text {th }} \mathrm{FYP}$; and 0.3075 , 0.3544 , and -0.1173 during the $12^{\text {th }}$ FYP. Compared with other provinces in this group, the decline degree of decoupling elasticity for the three provinces was not as obvious as for other provinces. That is to say the decoupling status during the $12^{\text {th }}$ FYP did not have a significant improvement compared with that in the $10^{\text {th }}$ and $11^{\text {th }}$ FYPs. Hainan has the relatively low economic output and $\mathrm{CO}_{2}$ emissions. But there is limited space for economic adjustment since the tertiary industry is already the pillar industry instead of the energyintensive second industry. Another thermal power generation was only $197 \times 10^{8} \mathrm{kWh}$, accounting for $0.46 \%$ of the national total, indicating that the emissionreduction and energy-saving space is restricted. As for Shaanxi, according to the study of $\mathrm{Xu}$, et al. (2017) [52], coal consumption for power generation would be growing gradually over time and the emissions from the power generation would be expected to show a downward trend in the future because of the strict measures to control emissions issued by the Shaanxi local government. This trend could be tested. The relative change of CE decreased from $93.29 \%$ during the $10^{\text {th }}$ FYP to $20.19 \%$ during the $12^{\text {th }}$ FYP; while the relative change of economic output maintained a steady situation. Gansu showed END during the $10^{\text {th }}$ FYP, EC during the $11^{\text {th }} \mathrm{FYP}$, and ideal SD at the end of the research period. Similar to Shaanxi, the relative change of GDP for Gansu maintained a steady level $(66.50 \%$, $52.45 \%, 55.11 \%$ ) for the three time phases. But the relative change of $\mathrm{CE}$ made a dramatic decline during 
the research period. During the $10^{\text {th }} \mathrm{FYP}$, the relative increase change value was $115.46 \%$, then it decreased to $53.70 \%$ during the $11^{\text {th }}$ FYP. During the $12^{\text {th }}$ FYP, the emissions exhibited a decline trend with $-6.47 \%$, which is attributed to the extraordinary achievement in renewable energy generation development during the $12^{\text {th }}$ FYP in the power industry. The first 10 million $\mathrm{kW}$ large-scale wind power base located in Jiuquan was built during the $12^{\text {th }}$ FYP due to the abundant wind resources in Gansu. That is the main reason for the SD status during the $12^{\text {th }}$ FYP. In 2016, several photothermal power generation projects, the first national pilots, were approved by the local government in order to fully utilize solar energy. It is predicted that $\mathrm{CE}$ in Gansu would be reduced sustainably and keep the goal decoupling status.

Based on the regional decoupling status evolution analysis, some implications could be drawn. (1) Some provinces (Shanxi, Inner Mongolia, Zhejiang, Hubei, Guangxi, and Qinghai) with the characteristics of transforming from expansive coupling to weak decoupling or strong decoupling status tested the implementation effect of economic development mode transformation and low-carbon achievement in the local power industry. (2) Some provinces (Jiangsu, Fujian, Jiangxi, Henan, Hunan, Guangdong, Sichuan, Guizhou, Yunnan, Ningxia) experienced three decoupling statuses, i.e., from expansive coupling in the $10^{\text {th }}$ FYP to weak decoupling in the $11^{\text {th }} F Y$, and weak decoupling or strong decoupling in the $12^{\text {th }}$ FYP. (3) The decoupling status for Shanghai and Tianjin (from weak decoupling to strong decoupling) indicated the effect of quality-production and emissions control policies from local government. (4) The decoupling evolution for some provinces (Anhui, Shandong and Xinjiang) is relevant to a local electricity project, showing the feature of abundant resources and high proportion of thermal power generation. (5) Certain provinces (like Hainan) showed limited space for economic adjustment because of the high tertiary industry and limited emissions control with a low proportion of energyintensive sectors. (6) A similar decoupling evolution might result from different reasons, like Shanxi and Gansu. The cause of decoupling evolution of Shaanxi involves the strict measures to control emissions issued by the Shaanxi local government, while the cause of Gansu involves wind power and the photothermal power generation projects. (7) There is no change of decoupling state for some provinces (Beijing and Chongqing) only with declined or fluctuating decoupling elasticity.

\section{Conclusions}

Based on the Tapio decoupling theory, this paper analyzed the decoupling relationship between the power industry-related indicators (CE and ECP) and economy from the national aspect. Then the regional decoupling analysis was implemented between the emissions and the economy from the provincial aspect. The concrete conclusions from the results and analysis could be listed as follows.

(1) In our work, four statuses (WD, SD, EC, and END) existed to describe the relationship between the power industry-related indictors and GDP among the eight decoupling statuses. Overall, decoupling status showed periodic characteristics.

(2) At the early- and mid-term of the research period, WD status between $\mathrm{CE}$ and GDP was the main form of decoupling state, except for EC status during the period of 2002-2006. During 2011-2012, the decoupling relationship showed abnormal END state because of the international nuclear accident and the corresponding generation policy adjustment in the national power industry. Since China entered the 'New Normal' economy, the decoupling relationship showed SD status, which indicated the effect of sustainable development in economic and energy fields, and especially the SD appeared at the period of 2008-2009 due to international sports events and the relevant energy-saving and emission-reduction polices.

(3) During most of the research period, the relationship of ECP and GDP showed END, WD, and EC, which means the ECP increases when GDP increases. However, SD status is not an ideal state because SD means that ECP decreases when GDP increases, which is different from the decoupling relationship between CE and GDP.

(4) The provincial decupling relationship between $\mathrm{CE}$ and GDP was investigated from three time phases. The decoupling status in some provinces remained unchanged during the research period; the decoupling status in some provinces changed from an unsatisfactory (EC, END, or WD, ) to an ideal state (SD); even the decoupling status in some provinces showed periodic characteristics, which is relevant to the regional development situation discussed in our work. In all, the empirical results indicate that the decoupling relationship varied in different regions of China at different time phases.

Based on the above conclusions, the policies or measures to achieve synergetic development of the economy and low-carbon development in the power industry could be inferred as follows.

First, the Chinese government should continue to promote the green and sustainable economic development mode. Since China entered the 'New Normal' economy, the decoupling relationship showed ideal SD status, which indicated that the economic development mode played an important role in decoupling evolution. Besides the optimization of economic structure, the cleaner development of China's industry should be promoted. In the future, the qualitybased instead of speed-based economic mode should be maintained.

Second, besides the measures of increasing the renewable-energy generation proportion and improving the efficiency in thermal power plant, in-depth steps 
from 'Further strengthening reform of power industry' should be emphasized to control the emissions from the power industry, such as: implementing price bidding, deploying energy storage, promoting the combined cooling heating and power to electric network, further strengthening the demand response, etc.

Third, introducing the public-private partnership (PPP) financing pattern into the power industry. The PPP model is a benign cooperation model of resource sharing and mutual help that has been implemented all over the world in different sectors, especially the energy sector. The Chinese National Energy Administration also issued the notice on actively promoting the cooperation of government and private capital in the energy field, encouraging the private capital to invest in the power energy industry. The potential cooperation aspects involve the generation project of distributed energy, the transformation and upgrading of distribution network, and so on. Thus, the PPP model is an effective way to make full use of renewable energy for power generation and to control emissions.

Fourth, accelerating the construction of the national smart grid. The national smart grid comes from the need to utilize renewable energy on a large scale. It can solve wind, solar and nuclear curtailment issues, and reduce the transmission and distribution loss to cope with the global climate.

Fifth, encouraging development of the Integrated Energy System (IES) - a combined system to accommodate distributed renewable energy and to realize the energy gradient utility. The IES system could improve energy efficiency and achieve clean production so as to combat more and more serious environmental problems and realize the synergetic development of the economy and power industry.

Sixth, combining the carbon market and the electricity market is the future effective means for emission-reduction. The power industry is an important participant in carbon emissions trading. It is reasonable to establish emissions cap-and-trade in the power industry and set an effective tax for coal-based plants.

All in all, to achieve the coordinated development of the economy and the power industry is the fundamental way to control emissions and increase electric carbon productivity.

\section{Acknowledgements}

This work was supported by the State Grid Corporation Science and Technology Project-Research on Time Sensitive Network Technology and Its Application in Distributed Energy Regulation (5700201919238A-0-0-00).

\section{Conflict of Interest}

The authors declare no conflict of interest

\section{References}

1. PAO H.T., FU H.C., TSENG C.L. Forecasting of $\mathrm{CO}_{2}$ emissions, energy consumption and economic growth in China using an improved grey model. Energy, 40 (1), 400, 2012.

2. IPCC. Climate Change. The Fourth Assessment Report of the Intergovernmental Panel on Climate Change. Cambridge University Press, England, 2007.

3. SUN W., CAI H., WANG Y. Refined Laspeyres Decomposition Based Analysis of Relationship between Economy and Electric Carbon Productivity from the Provincial Perspective - Development Mode and Policy. Energies, 11 (12), 3426, 2018.

4. CEC (China Electric Council). China's Electric Power Statistical Yearbook 2018. China's Electric Power Press, Beijing, China, 2019.

5. NBSC (National Bureau of Statistics of China). China Statistical Yearbook. China Statistics Press, China, 2018.

6. EIA (Energy Information Administration). ChinaInternational analysis, 2016. https://energy.gov/sites/prod/ files/2016/04/f30/China_International_Analysis_US.pdf (accessed on 15 September 2019).

7. CUI L.B., FAN Y., ZHU L., BI Q.H. How will the emissions trading scheme save cost for achieving China's 2020 carbon intensity reduction target? Applied Energy, 136, 1043, 2014.

8. National Development and Reform Commissions of China (NDRC). Enhanced Actions on Climate Change: China's Intended Nationally Determined Contributions, 2018. http://www4.unfccc.int/submissions/INDC/Published $\% 20$ Documents/China/1/China's\%20INDC\%20-\%20on\%20 30\%20June\%202015.pdf (accessed 13 September 2019).

9. CHEN A., GROENEWOLD N. China's 'New Normal': Is the growth slowdown demand-or supply-driven? China Economic Review, 58, Article 101203, 2019.

10. MIKAYILOV J.I., HASANOV F.J., GALEOTTI M. Decoupling of $\mathrm{CO}_{2}$ emissions and GDP: A time-varying cointegration approach. Ecological Indicators, 95, 615, 2018.

11. WU Y., ZHU Q., ZHU B. Decoupling analysis of world economic growth and $\mathrm{CO}_{2}$ emissions: A study comparing development and developing countries. Journal of Cleaner production, 190, 94, 2018.

12. CHEN J., WANG P., CUI L., HUANG S., SONG M. Decomposition and decoupling analysis of $\mathrm{CO}_{2}$ emissions in OECD. Applied Energy, 231, 937, 2018.

13. PAO H., CHEN C. Decoupling strategies: $\mathrm{CO}_{2}$ emissions, energy resources, and economic growth in the Group of Twenty. Journal of Cleaner production, 206, 907, 2019.

14. VAVREK R., CHOVANCOVA J. Decoupling of greenhouse gas emissions from economic growth in V4 countries. Procedia Economics \& Finance, 39, 526, 2016.

15. GUEVARA Z., DOMINGOS T. Three-level decoupling of energy use in Portugal 1995-2010. Energy Policy, 108, 134, 2017.

16. WANG Q., WANG S. Decoupling economic growth from carbon emissions growth in the United States: The role of research and development. Journal of Cleaner Production, $234702,2019$.

17. ROINIOTI A., KORONEOS C. The decomposition of $\mathrm{CO}_{2}$ emissions from energy use in Greece before and during the economic crisis and their decoupling from economic growth. Renewable \& Sustainable Energy Reviews, 76, 448, 2017. 
18. FREITAS L.C.D., KANEKO S. Decomposing the decoupling of $\mathrm{CO}_{2}$ emissions and economic growth in Brazil. Ecological Economics, 70 (8), 1459, 2011.

19. WANG Q., JIANG R. Is China's economic growth decoupled from carbon emissions? Journal of Cleaner Production, 225, 1194, 2019.

20. RITI J.S., SONG D., SHU Y., KAMAH M. Decoupling $\mathrm{CO}_{2}$ emission and economic growth in China: Is there consistency in estimation results in analyzing environmental Kuznets curve? Journal of Cleaner Production, 166, 1448, 2017.

21. LIN B., WANG M. Possibilities of decoupling for China's energy consumption from economic growth: A temporalspatial analysis. Energy, 185 (15), 951, 2019.

22. WANG Q., ZHAO M., LI R., SU M. Decomposition and decoupling analysis of carbon emissions from economic growth: a comparative study of China and the United States. Journal of Cleaner Production, 197, 178, 2018.

23. SONG Y., ZHANG M., ZHOU M. Study on the decoupling relationship between $\mathrm{CO}_{2}$ emissions and economic development based on two-dimensional decoupling theory: A case between China and the United States. Ecological Indicators, 102, 230, 2019.

24. WANG Q., JIANG R., ZHAN L. Is decoupling economic growth from fuel consumption possible in developing countries? e A comparison of China and India. Journal of Cleaner Production, 229, 806, 2019.

25. WANG X., WEI Y., SHAO Q. Decomposing the decoupling of $\mathrm{CO}_{2}$ emissions and economic growth in China's iron and steel industry. Resources, Conservation and Recycling, 152, Article 104509, 2020.

26. WANG Q., WANG S. A comparison of decomposition the decoupling carbon emissions from economic growth in transport sector of selected provinces in eastern, central and western China. Journal of Cleaner Production, 229, $570,2019$.

27. LUO Y., LONG X., WU C., ZHANG J. Decoupling $\mathrm{CO}_{2}$ emissions from economic growth in agricultural sector across 30 Chinese provinces from 1997 to 2014. Journal of Cleaner Production, 159, 220, 2017.

28. WU Y., CHAU K.W., LU W., SHEN L., SHUAI, C., CHEN J. Decoupling relationship between economic output and carbon emission in the Chinese construction industry. Environmental Impact Assessment Review, 71, 60, 2018.

29. MENG M., FU Y., WANG X. Decoupling, decomposition and forecasting analysis of China's fossil energy consumption from industrial output. Journal of Cleaner Production, 177, 752, 2018.

30. HANG Y., WANG Q., ZHOU D., ZHANG L. Factors influencing the progress in decoupling economic growth from carbon dioxide emissions in China's manufacturing industry. Resources, Conservation \& Recycling, 146, 77, 2019.

31. MA M., CAI W., CAI W., DONG L. Whether carbon intensity in the commercial building sector decouples from economic development in the service industry? Empirical evidence from the top five urban agglomerations in China. Journal of Cleaner Production, 222, 193, 2019.

32. ZHOU X., ZHANG M., ZHOU M., ZHOU M. A comparative study on decoupling relationship and influence factors between China's regional economic development and industrial energy-related carbon emissions. Journal of Cleaner Production, 142, 783, 2017.

33. JIANG J., YE B., ZHOU N., ZHANG X. Decoupling analysis and environmental Kuznets curve modelling of provincial-level $\mathrm{CO}_{2}$ emissions and economic growth in
China: A case study. Journal of Cleaner Production, 212, 1242, 2019.

34. COHEN G., JALLES J.T., LOUNGANI P., MARTO R., WANG G. Decoupling of emissions and GDP: Evidence from aggregate and provincial Chinese data. Energy Economics, 77, 105, 2019.

35. WU Y., TAM V.W.Y., SHUAI C., SHEN L., ZHANG Y., LIAO S. Decoupling China's economic growth from carbon emissions: Empirical studies from 30 Chinese provinces (2001-2015) . Science of the Total Environment, 656, 576, 2019.

36. WANG Q., ZHAO M., LI R. Decoupling sectoral economic output from carbon emissions on city level: A comparative study of Beijing and Shanghai, China. Journal of Cleaner Production, 209, 126, 2019.

37. LU Q., YANG H., HUANG X., CHUAI X., WU C. Multisectoral decomposition in decoupling industrial growth from carbon emissions in the developed Jiangsu Province, China. Energy, 82, 414, 2015.

38. XIE P., GAO S., SUN F. An analysis of the decoupling relationship between $\mathrm{CO}_{2}$ emission in power industry and GDP in China based on LMDI method. Journal of Cleaner Production, 211, 598, 2019.

39. ZHANG C., SU B., ZHOU K. YANG S. Analysis of electricity consumption in China (1990-2016) using index decomposition and decoupling approach. Journal of Cleaner Production, 209, 224, 2019.

40. HAO Y., ZHANG T., JING L., XIAO L. Would the decoupling of electricity occur along with economic growth? Empirical evidence from the panel data analysis for 100 Chinese cities. Energy, 180, 615, 2019.

41. TAN Z., LI L., WANG J., WANG J. Examining the driving forces for improving China's $\mathrm{CO}_{2}$ emission intensity using the decomposing method. Applied Energy, 88 (12), 4496, 2011.

42. KAYA Y., YOKOBORI K. Environment, Energy, and Economy: Strategies for Sustainability. United Nations University Press, Tokyo, Japan, 1997.

43. WANG Y., XIE T., YANG S. Carbon emission and its decoupling research of transportation in Jiangsu Province. Journal of Cleaner Production, 142 (Part 2), 907, 2017.

44. SANYÉ-MENGUAL E., SECCHI M., CORRADO S., BEYLOT A., SALA S. Assessing the decoupling of economic growth from environmental impacts in the European Union: A consumption-based approach. Journal of Cleaner Production, 236, Article 117535, 2019.

45. TAPIO P. Towards a theory of decoupling: degrees of decoupling the EU and the case of road traffic in Finland between 1970 and 2001. Transport Policy, 12 (2), 137, 2005.

46. NBSC (National Bureau of Statistics of China). China Statistics Yearbook 2001-2017. China Statistics Press, Beijing, China.

47. CEC (China Electric Council). China's Electric Power Statistical Yearbook 2001-2017. China's Electric Power Press, Beijing, China.

48. National Development and Reform Commission (NDRC). Medium and long term plan for renewable energy development, July 2007.

49. National Development and Reform Commission (NDRC). Medium and long term plan for nuclear energy development (2005-2020), October 2007.

50. Chinese Wind Energy Association (CWEA). Statistics of China's wind power installed capacity. Beijing: CWEA, 2005-2010. 
51. HONG L., ZHOU N., FRIDLEY D., RACZKOWSKI C. Assessment of China's renewable energy contribution during the 12th Five Year Plan. Energy Policy, 62, 1533, 2013.
52. XU Y., HU J., YING Q., HAO H., WANG D., ZHANG H. Current and future emissions of primary pollutants from coal-fired power plants in Shaanxi, China. Science of the Total Environment, 595, 505, 2017. 